\title{
Reproductive Process
}

National Cancer Institute

\section{Source}

National Cancer Institute. Reproductive Process. NCI Thesaurus. Code C21173.

A Reproductive System Process involves a function of cellular, cell, or tissue components of the organ system involved in generation of offspring that includes the ovaries, fallopian tubes, uterus, cervix, and vagina in women or the prostate, testes, and penis in men. 